\title{
ASO Author Reflections: The Safety of Oncoplastic Surgery for Multicentric and Multifocal Breast Tumors
}

\author{
Francesca de Lorenzi, MD, PhD, and Francesco Borelli, MD \\ Department of Plastic and Reconstructive Surgery, European Institute of Oncology, IRCCS, Milan, Italy
}

\section{PAST}

The approach to breast cancer surgery has evolved significantly during recent decades. The change from radical mastectomy to breast-conserving technique represents a move toward less disruptive targeted surgical procedures with no loss oncologic safety. ${ }^{1}$ Oncoplastic surgery (ONC), the direct consequence of that evolution, merges breastconserving surgery and plastic surgery technique with the aim of eradicating the tumor and reducing breast deformity. ${ }^{2}$ In a previous study, the authors demonstrated that the ONC approach is safe and effective as a treatment for invasive pT2 breast cancer. ${ }^{3}$ To date, long-term oncologic follow-up studies on the use of oncoplastic technique for multifocal and multicentric breast cancer are lacking.

\section{PRESENT}

This study was a single-center retrospective matchedcohort analysis comparing patients who had multicentric or multifocal breast tumors treated with oncoplastic technique (study group) and patients with multicentric or multifocal tumors who had undergone mastectomy (control group). The study results showed that the disease-free and the overall survival rates were similar in the two groups suggesting that the oncoplastic approach is safe and effective for multifocal and multicentric breast cancer. ${ }^{4}$

(C) Society of Surgical Oncology 2021

First Received: 3 September 2021

Accepted: 4 September 2021;

Published Online: 26 September 2021

F. de Lorenzi, MD, PhD

e-mail: francesca.delorenzi@ieo.it

\section{FUTURE}

In the authors' opinion, oncoplastic surgery is the present and future of breast cancer surgery. To help its widespread adoption and to guide surgeons in their clinical practice, more long-term follow-up studies are warranted. Future studies should be implemented as randomized clinical trials focused on the biologic features of multiple ipsilateral breast cancers to confirm the safety of ONC for multifocal and multicentric tumors.

DISCLOSURE There are no conflict of interest.

\section{REFERENCES}

1. Fisher B, Redmond C, Poisson R, et al. Eight-year results of a randomized clinical trial comparing total mastectomy and lumpectomy with or without irradiation in the treatment of breast cancer. N Engl J Med. 1989;320:82.

2. Chatterjee A, Gass J, Patel K, Holmes D, Kopkash K, Peiris L, et al. A consensus definition and classification system of oncoplastic surgery developed by the American Society of Breast Surgeons. Ann Surg Oncol. 2019;26:3436-44. https://doi.org/10. 1245/s10434-019-07345-4.

3. De Lorenzi F, Hubner G, Rotmensz N, Bagnardi V, Loschi P, Maisonneuve P, et al. Oncological results of oncoplastic breastconserving surgery: long term follow-up of a large series at a single institution: a matched-cohort analysis. Eur J Surg Oncol. 2016;42:71-7. https://doi.org/10.1016/j.ejso.2015.08.160.

4. De Lorenzi F, Borelli F, Pagan E, Bagnardi V, Peradze N, Jereczek-Fossa B, et al. Oncoplastic breast-conserving surgery for synchronous multicentric and multifocal tumors: is it oncologically safe? A retrospective matched-cohort analysis. Ann Surg Oncol. https://doi.org/10.1245/s10434-021-10800-w.

Publisher's Note Springer Nature remains neutral with regard to jurisdictional claims in published maps and institutional affiliations. 